\title{
DIA DOS MORTOS E A VIVÊNCIA DO LUTO: RELATO DE EXPERIÊNCIA
}

Izabela Aparecida de Almeida Guedes

Pontifícia Universidade Católica de São Paulo

Maria Carolina Rissoni Andery

Pontifícia Universidade Católica de São Paulo

Claudia Marques Comaru

Pontifícia Universidade Católica de São Paulo
Recebido em: 04/05/2020

$1^{\text {a }}$ revisão em: 13/10/2020

$2^{a}$ revisão em: 16/02/2021

Aceito em: 15/05/2021

\section{RESUMO}

O luto envolve dimensões individuais, familiares, socioculturais e espirituais, demandando do psicólogo abertura para dialogar com outras áreas de conhecimento, visando ampliar a compreensão da experiência de quem sofre a perda de alguém significativo. Este trabalho objetiva relatar a participação de três psicólogas brasileiras na festa do Dia dos Mortos, em Ocotepec, México. O método utilizado foi a etnografia, com registro das observações em diário de campo individuais. Observou-se a importância dos rituais para o enfrentamento do luto e suas diferentes expressões. A presença de diversos símbolos que resgatam a lembrança da pessoa falecida, preservando sua memória, possibilitou considerar o modelo de vínculos contínuos no enfrentamento de uma perda significativa. A morte é celebrada e versada coletivamente no México, enquanto é tema tabu no Brasil. A vivência desses ritos possibilitou compreender os atravessamentos sociais e culturais da morte e do luto, experiência salutar para a construção de uma clínica ampliada.

Palavras-chave: dia dos mortos; México; rituais de morte; luto; vínculos contínuos. 


\title{
DAY OF THE DEAD AND THE EXPERIENCE OF BEREAVEMENT: EXPERIENCE SAMPLING
}

\begin{abstract}
Bereavement involves individual, familial, social, cultural and spiritual dimensions, demanding that psychologists open to dialogue with other areas of knowledge, aiming to broaden the understanding of the experience of those who suffer the loss of someone significant. This work aims to report the participation of three psychologists in the Day of the Dead party, in Ocotepec, Mexico. The method used was ethnography, with observations recorded in individuals field diaries. The presence of several symbols that recover the memory of the deceased person, preserving their memory, made it possible to consider the model of continuous bonds in coping with a significant loss. Death is celebrated and versed collectively in Mexico, while it is a taboo subject in Brazil. The experience of these rites made it possible to understand the social and cultural crossings of death and grief, a healthy experience to build an expanded clinic.
\end{abstract}

Keywords: day of the dead; México; death rites; grief; continuous bonds.

\section{DÍA DE LOS MUERTOS Y EL LUTO: NARRACIÓN DE LA EXPERIENCIA}

\section{RESUMEN}

El duelo involucra dimensiones individuales, familiares, socioculturales y espirituales que exigen del psicólogo apertura para dialogar con otras áreas del conocimiento, ampliando la comprensión de la experiencia de aquel que sufre la pérdida de alguien significativo. Este trabajo relata la participación de psicólogas brasileñas en la fiesta del Día de Muertos en Ocotepec, México. El método utilizado fue la etnografía, con registro de observaciones en diarios de campo. Se observó la importancia de los rituales en el afrontamiento del duelo. La presencia de símbolos que rescatan el recuerdo de la persona fallecida permitió considerar el modelo de enlaces continuos en el afrontamiento de una pérdida significativa. La muerte es celebrada y reconocida colectivamente en México, mientras que en Brasil es un tema tabú. La vivencia de estos rituales permitió comprender las intersecciones sociales y culturales de la muerte y el duelo, experiencia benéfica para la construcción de una clínica ampliada.

Palabras clave: día de los muertos; México; ritos de muerte; luto; vínculos continuos. 


\section{INTRODUÇÃO}

O Dia dos Mortos ${ }^{1}$, no México, é elemento de identidade do povo, manifestação cultural transcendente e significativa dos povos indígenas mexicanos, que prevalece em torno das celebrações dedicadas aos mortos nas cidades e nas populações rurais (CONACULTA, 2006). Sua origem é, portanto, anterior à chegada dos espanhóis, herança dos povos originários que habitavam aquela região, como os maias, astecas e incas, para citar alguns dos principais. Segundo Konno (2018), a festa passou a ser reconhecida como Patrimônio Cultural Imaterial da Humanidade em 2003. Atualmente, ela acontece durante alguns dias e foi incorporada às festividades da Igreja Católica, datas correspondentes ao Dia de Todos os Santos (01/11) e ao Dia de Finados (02/11).

Toda cultura tem seus rituais próprios para lidar com a morte, o que está relacionado com crenças e heranças de culturas antepassadas. Rituais de despedida e rituais de preservação da memória de um ente querido falecido são relevantes para a vivência de um processo de luto, quer dizer, a realização de rituais que façam sentido para a cultura do enlutado, seja ela a familiar ou da comunidade no qual o indivíduo está inserido. No caso do México, em alguns lugares menores e mais afastados da Capital, é possível encontrar a tradição préhispânica preservada, como acontece em Ocotepec, onde os moradores locais resistem para manter vivo o costume de lembrar e honrar seus mortos. Estar nesse povoado, durante as comemorações do Dia dos Mortos, foi uma experiência enriquecedora para o nosso olhar curioso de cientistas, interessadas em aprofundar em temas relacionados ao luto, além de ter sido uma vivência intensa e transformadora do ponto de vista da experiência pessoal.

Segundo Botelho, Darcie \& Gobbi (2019, p.203), o Dia dos Mortos nasceu de manifestações populares espontâneas, mostrando sua força nas casas mexicanas e revelando ao mundo suas cores, sabores e uma forma diferente de olhar a morte. "Como processo cultural e, sobretudo, comunicacional", enquadrando-se nas festas de caráter espontâneo, pois são representadas por comemorações em conjunto com a população e inclui festejos folclóricos. É possível identificar a fala desses autores na movimentação da cidade visitada: há transmissão cultural oral por meio da fala das pessoas -, comunicando como são desenvolvidos os rituais e demonstrando interesse em apresentar aspectos coletivos e individuais que acontecem nos dias em que recebem seus entes queridos que morreram, ou seja, quando os recebem em casa e no cemitério, oferecendo comidas, brinquedos, músicas, roupas, recordações, de acordo com a idade e o gosto pessoal da pessoa que faleceu.

Posto isso, neste artigo, temos como objetivo apresentar os rituais de celebração do Dia dos Mortos no ano de 2018 conforme eles acontecem no vilarejo de Ocotepec, distrito de Cuernavaca, situado no estado de Morelos/México, de forma a poder ampliar a discussão a respeito da relação entre morte, o morrer e os processos de luto. 
As festividades se iniciam no dia 29 de outubro e se estendem até o dia 2 de novembro. Como apresentou Lemos (2009a), a festa possui caráter individual, comunitário, eclesiástico ou institucional. A celebração ocorre tanto na intimidade das casas como nas ruas, cemitérios e igrejas. A manifestação cultural da festa do dia dos mortos não só ativa, como reforça, princípios de afetividade, reciprocidade, solidariedade e pertencimento, valorizados pelo povo mexicano.

Durante esse tempo, as autoras acompanharam a composição de alguns rituais que fazem parte da festividade. Entre eles, a visita aos altares nas casas das famílias onde algum ente querido tivesse morrido no último ano (quer dizer, no período desde a festividade do ano anterior); a preparação dos túmulos pelos familiares; a participação nos ritos religiosos durante a celebração comunitária, no cemitério. Esse caleidoscópio de vivência suscitou reflexões em torno de temas que permeiam os estudos sobre o luto, áreas que devem se manter em permanente questionamento, como, a participação da cultura da morte na forma com que os indivíduos viverão a perda de um ente querido.

Foi possível perceber uma forte presença do sincretismo religioso em momentos diversos, como aqueles em que se mesclaram rituais herdados da cultura indígena reproduzidos nos pátios ou na parte interna das igrejas católicas, sendo possível testemunhar exaltação aos espíritos e reverência aos elementos da natureza (água, terra, fogo e ar) em meio a imagens de santos e de Nossas Senhoras. Botelho et al (2019), ao discutirem o assunto, disseram que a festividade demonstra a força da tradição indígena no México, mesmo após intervenção espanhola cristã, em que vida e morte invadem-se mutuamente. Conforme o Cuaderno 16, La festividad indígena (Conaculta, 2006, p. 32):

as festividades do dia dos mortos são uma representação da identidade, uma recriação das origens de um povo sincrético e sintético. Sintetizam-se, somam-se os corpos, as ideologias e os sistemas culturais, misturando não só nossas características físicas, mas também nossas mentalidades e saberes. [tradução livre]

Neste artigo, primeiramente será feita uma exposição sobre a festa do Dia dos Mortos, assim como particularidades vistas, vividas e sentidas. Impressões que foram registradas em diários de campo, fotografias, observação ativa e conversas com os moradores do local que auxiliaram na composição desses registros. O contato com textos que abordam o assunto forneceu subsídios teóricos para uma melhor compreensão da festa, tão farta em detalhes e símbolos.

Com relação ao tema do luto, será feita uma contextualização sobre a participação dos rituais nas vivências da perda de um ente querido, assim como serão apresentadas abordagens atuais, que se propõem a trazer uma visão contemporânea sobre o assunto, por exemplo, o modelo dos vínculos contínuos (Silverman \& Klass (1996); Silverman \& Nickman, (1996); Rosenblatt, (1996)) e o modelo do processo dual (Stroebe \& Schut, 1999). Esse conjunto de 
conhecimentos é basal na prática dos profissionais que atuam com enlutados, sejam adultos ou crianças, podendo auxiliar na compreensão e no acompanhamento do processo, visando que sejam atenuados os riscos do desenvolvimento de um luto complicado. Por essa razão, são temas que necessitam de reflexão e aprofundamento constantes em suas bases teóricas.

Sendo assim, a partir do compartilhamento de reflexões iniciadas ainda durante a estada em Ocotepec, serão tecidas considerações procurando-se estabelecer relações entre os temas, assim como correlacioná-las às leituras encontradas, que foram essenciais à escrita do presente artigo.

Isso posto, passará a ser apresentada a experiência vivida em Ocotepec, partindo das explicações que foram transmitidas através da oralidade e, posteriormente, por meio de publicações encontradas a respeito da festividade. Com isso, objetiva-se aproximar o leitor dessa experiência, despertando-lhe curiosidade e inquietações a respeito da cultura da morte do processo de morrer, visando que isso possibilite incrementar as reflexões sobre a participação sócio-histórica nos processos individuais de luto.

\section{MÉTODO}

O método utilizado foi o da etnografia por ser, como nos contou Creswell (2014), um projeto qualitativo que tem uma forma de estudar um grupo, seus significados, linguagem, interação e compartilhamento da cultura por meio da observação participante. "Em uma etnografia, o pesquisador busca padrões (também descritos como rituais, comportamento sociais costumeiros ou regularidades) das atividades mentais do grupo, como as suas ideias e crenças expressas por meio da linguagem, ou atividades materiais" (Creswell, 2014, p. 83).

Observamos os rituais presentes naquele povoado referentes às festividades do Dia dos Mortos, o que nos permitiu compreender a cultura e as regras presentes naquela população por meio da observação participante e diálogo com os moradores, enquanto caminhávamos pelo local e adentrávamos a intimidade das casas, para conhecer os altares. Um ponto importante a ser ratificado a respeito do presente artigo é que ele reúne as percepções de três pesquisadoras e clínicas no trabalho com pessoas enlutadas.

Foram frequentados três dias da festividade, em que se procurou observar a forma como os rituais aconteciam e como as pessoas os vivenciavam, se relacionavam e conviviam com os visitantes. Durante a visita a uma das casas, onde a pessoa falecida era uma senhora, três crianças moradoras do povoado aproximaram-se, em companhia de alguns familiares, ao perceberem tratar-se de pessoas estrangeiras e ao notarem um genuíno interesse pelo que acontecia no local. Elas ficaram curiosas sobre a língua que falávamos e sobre o país de onde vínhamos, ao mesmo tempo em que faziam várias perguntas sobre nossa origem, gostavam de ir mostrando e contando tudo o que acontecia na cidade deles, em especial naqueles dias. Também fez parte da calorosa acolhida eles nos 
acompanharem durante todo o dia, levando até cada casa com altar, contando as histórias de cada uma, de cada pessoa.

A observação participante e o diário de campo das três pesquisadoras foram instrumentos fundamentais de coleta de dados, possibilitado captar o máximo possível de informações, que foram contextualizadas de acordo com os textos acadêmicos referentes ao tema encontrados, posteriormente, ao longo da fase de pesquisa bibliográfica. De acordo com Minayo (2004), a observação participante pode ter uma forma livre ou roteirizada, e seu conteúdo pode ser mais abrangente ou dar ênfase a alguns elementos mais específicos, sendo esses os aspectos principais a serem levados em conta quando da sua utilização. Entendemos que essas características apontam para uma observação mais flutuante e aberta ao meio ambiente, por um lado, enquanto requer foco e atenção a determinadas informações, por outro. O diário de campo (ou diário de pesquisa) foi o instrumento utilizado para registrar as informações colhidas por meio da observação, no qual podem ser anotadas impressões pessoais, conversas informais, comportamentos, gestos, expressões (Minayo, 2004), as quais podem trazer contribuições sobre o campo de pesquisa, de notável riqueza à temática estudada, não devendo, portanto, serem desprezadas.

Segundo orientação de Creswell (2014), no caso do método etnográfico, a análise dos dados deverá ser feita a partir da descrição do funcionamento de um grupo que compartilha determinada cultura.

Os aspectos éticos foram seguidos de acordo com as pesquisas sem entrevistas com seres humanos, o que dispensou a necessidade de submissão do trabalho a um comitê de ética, tendo sido as informações colhidas por meio da observação participante e da imersão das autoras no campo de investigação.

\section{VIVÊNCIA DO DIA DOS MORTOS EM OCOTEPEC E SUAS RELAÇÕES COM O LUTO}

As celebrações do Dia dos Mortos, por toda a extensão do México, contêm elementos semelhantes e partem da mesma base de significação. Cada localidade, no entanto, costuma apresentar diferentes enfoques e manifestações da fé. Em Ocotepec, a tradição permanece com os dias destinados a receber as almas de falecidos por mortes trágicas (29/10), crianças (31/10) e adultos (1/11). Acredita-se que as almas partem do mundo dos mortos e seguem rumo à casa de sua família, para passar o dia na companhia dos seus, respectivamente. No dia $2 / 11$, todas as famílias vão ao cemitério celebrar com música, comida, altares e/ou flores, a despedida de seus entes queridos, quando estes retornam para o mundo dos mortos.

Segundo Saporetti \& Silva (2012, p.561), "além de garantir ao falecido seu caminho no plano imaterial, os ritos pretendem dar aos entes que ficam o conforto e a possibilidade de vivenciar a morte numa dimensão transcendente". $\mathrm{Na}$ festa do Dia dos Mortos, os rituais têm sua importância para o processo de 
luto, tais como o das visitas às casas, que podem ser feitas por familiares e enlutados, assim como por desconhecidos e/ou turistas, pois há expectativa dos moradores quanto à chegada desse momento, o que foi percebido através de conversas informais ouvidas durante as caminhadas pelo povoado.

Às doze horas de cada um dos dias de celebrações, o sino da igreja é badalado para marcar o início do período em que os falecidos seguem rumo às suas casas. Acontece, então, a ceriada (em espanhol, palavra que faz referência à cera da vela), momento em que as velas são entregues aos familiares, como retribuição ao compartilhamento do altar, da comida e da bebida, geralmente sendo estas depositadas ao lado ou aos pés do altar que homenageia o ente querido falecido. Além das velas - as pequenas devem ser ofertadas aos mortos crianças e as grandes aos mortos adultos -, os visitantes também devem levar consigo uma caneca de cerâmica, utilizada para receber a bebida oferecidas pelas famílias ao final da visita, devendo o visitante sempre primar por evitar o desperdício como forma de respeito às famílias. A caneca é utilizada para diminuir os altos custos que os familiares têm para a confecção dos altares, por ser uma forma sustentável de a comunidade comungar da festa, e para prevenir a proliferação de doenças.

Logo na entrada das casas, é possível avistar a expressão "bem-vindo", onde se inicia um caminho feito por pétalas da flor cempasúchil, que, como Lemos (2009a) apontou, simboliza a morte pelo seu odor desagradável. Essa flor teria como função facilitar a identificação pelas almas dos falecidos por sua cor amarela forte. O caminho tem o intento de relembrar à alma do falecido a rota de volta para casa - é a primeira vez em que ele está retornando do mundo dos mortos - e, além das flores, esse caminho contém velas acesas, para iluminar a chegada. Diferentes cores e formas de papéis de seda recortados, chamados de papel picado, balançam ao sabor do vento, o que se acredita que faça alegrar o espírito daquele que morreu. Os visitantes percorrem toda a casa através desse caminho, que pode se estender por alguns metros da entrada e que parece se desenhar como uma ponte entre a vida e a morte. É uma experiência sensorial abundante, em que há uma explosão de cores, cheiros e sons, ao mesmo tempo em que muitos novos códigos vão sendo informados e precisam ser apreendidos.

Como disse Guedes (2018), nenhum enlutado deseja se sentir abandonando uma pessoa importante que morreu. Quem perde um ente querido quer destiná-lo a um espaço de amor, de onde possa se aproximar, quando necessário, a fim de obter conforto, amenizar a saudade, sentir-se protegido. Dessa forma, o enlutado precisa construir um novo relacionamento com a pessoa falecida, aprendendo a estabelecer novas conexões, de maneira que o vínculo e a ligação com o ente querido se mantenham, apesar da ausência física. Silverman \& Klass (1996), Rosenblatt (1996) e Silverman, \& Nickman (1996) chamaram de vínculo contínuo essa ligação que se perpetua no tempo, ou seja, a representação interna que é reconstruída a partir do sistema de crenças, da visão de mundo e do relacionamento que existia entre a pessoa enlutada e a pessoa falecida. 
Ao entrar na casa, facilmente se avista a oferenda (o altar) da família dedicada ao seu ente querido e é comum que seja escolhida uma seleção musical, da preferência da pessoa falecida, para compor a homenagem. Aos visitantes são oferecidos um pedaço do pão do morto (como é chamado o pão caseiro feito especialmente para essa ocasião) e uma caneca de chá, a serem consumidos no espaço externo da casa, em geral um quintal, onde permanecem em torno de 20 a 30 minutos, a depender do grau de proximidade com a família. A comunidade também pode levar comida para contribuir com a casa que abre suas portas, o que, tomando como referência festividades e os ritos da cultura brasileira, poderíamos identificar como sendo um misto de pesar de velório com festa de aniversário.

As oferendas têm como finalidade reverenciar os falecidos e suas histórias, consistindo em altares com fotos e elementos que simbolizam como foi aquela vida: roupas, objetos, comidas e bebidas. Os altares diferem de tamanho a depender do tempo de falecimento. Aos defuntos novos, é construída uma oferenda maior, na qual faz-se uma representação do corpo deitado no caixão com um crânio de açúcar no lugar da cabeça, inclusive, valendo ressaltar, uma peculiaridade exclusiva da festividade que acontece em Ocotepec.

Segundo Rodríguez, Moreno \& Méndez (2012 [tradução nossa]), o altar é um elemento que representa o sincretismo; os mais comuns são os altares de dois níveis, que representam o céu e a terra; os de três níveis, acrescentam a visão de purgatório; e o mais tradicional é o altar de sete níveis, que simboliza os passos necessários para alcançar o céu e poder descansar. Os autores contaram, ainda, que as etapas/passos estão alinhadas em preto e branco; no primeiro passo é colocada a imagem de um santo, a quem ele é dedicado; o segundo é para as almas do purgatório; no terceiro, o sal é colocado e simboliza a purificação do espírito para os filhos do purgatório. No quarto, é oferecido o pão (elemento central da festa de Dia dos Mortos) como alimento às almas que lá estão; no quinto, são colocadas as frutas e os alimentos favoritos do falecido; no sexto, as fotografias de pessoas que morreram e são lembradas através do altar; e, no sétimo passo, uma cruz composta de sementes ou frutos, como tejocote e limão. Conforme contou o Laboratório de Consciência Digital ${ }^{2}$, em cada oferenda estão representados elementos naturais, tais como: água, terra, fogo, vento, sementes e flores, velas e papel picado, como era o costume nas épocas antigas.

Aos defuntos com tempo de morte superior a um ano, são construídos altares mais simples e discretos, não sendo comum às famílias continuar abrindo as portas da casa para a comunidade. A comemoração, portanto, ganha um caráter mais privado, reservado ao familiar, em contraponto a celebrar o primeiro ano da morte, que têm um aspecto público relevante, pois trata-se de compartilhar com a comunidade a morte atual dos entes queridos. O mesmo acontece no dia 02 de novembro, pois os túmulos podem receber apenas flores e poucas pessoas ou nenhum familiar podem visitá-lo no decorrer do dia, além de que nem sempre as simples oferendas costumam ser levadas ao cemitério. 
A seguir, serão descritas e discutidas algumas visitas realizadas Nos dias 31 de outubro e 1 de novembro, dessa forma buscando apresentar e ilustrar algumas de suas peculiaridades que representam as reflexões suscitadas.

A primeira visita de bem-vindo à criança aconteceu na noite do dia 31 de outubro, em uma casa que foi reconhecida por haver, no portão, um grande mural de flores com boas-vindas e os nomes de duas pessoas falecidas. Na parte interna, logo na entrada, havia um quadro apresentando fotos de um menino de 7 anos e de sua avó. Nesse dia, uma dedicação maior foi dada à oferenda dedicada à criança, havendo dois altares para ela: um, exclusivamente, com brinquedos, máscaras, roupas de super-heróis, e o segundo, em outro cômodo, ao lado do altar da avó. Um jovem casal recebia as velas ofertadas pelos visitantes, mantendo uma postura silenciosa; deixavam a impressão de serem os pais da criança. Os demais visitantes apresentavam olhares cabisbaixos e um tom cerimonioso de respeito, remetendo aos rituais de despedida praticados no Brasil. No quintal, os muros estavam pintados com personagens de histórias infantis, como Bambi, Coco, além das trilhas sonoras desses e de outros desenhos animados, que tocavam em alto-falantes espalhados pelos canteiros.

Tal situação ilustra o quanto o rompimento de um vínculo por morte tem um potencial desorganizador do mundo presumido ${ }^{3}$ que precisa ser ressignificado, re-construído. Para cada perda, há possibilidade de ocorrerem outras, chamadas de perdas secundárias (Parkes, 1998), como, de papéis sociais, financeiras, eventuais mudanças de endereço/casa, entre outras. Essa reorganização do mundo interno acontece de acordo com o vínculo com a pessoa que morreu, estando relacionada com o estilo de apego entre o enlutado e a pessoa falecida, pois, como mostraram Bowlby (1969/2002) e Parkes (2009), os vínculos são nossas fontes de segurança e de apoio frente a ameaças.

O primeiro dia de novembro, dia de bem-vindo aos adultos, iniciou-se com a visita a uma casa, que convidava à entrada com o caminho de flores desde a calçada. Numa primeira sala, encontrava-se um grande quadro de fotos representando cenas da vida familiar. Um homem, ao pé dos altares, recebia as velas ofertadas pelos visitantes; nessa casa, havia três falecidos: um casal de idosos e o cunhado deles. Foi contado que a morte do casal havia acontecido havia poucos meses, a partir de um pacto: ambos morreram buscando alívio para acometimentos provocados por uma doença crônica, em estágio avançado de evolução, sendo que o marido tirou a vida da esposa e, em seguida, a própria. Tal acordo era de conhecimento da família, informação que foi partilhada com muita discrição. O cunhado tinha morrido havia três semanas, de morte natural. Alguns familiares estavam chegando ao local e o clima da casa era de pesar, devendo-se levar em conta que uma das mortes era muito recente e alguns visitantes estavam se reunindo com a família enlutada pela primeira vez após a perda do ente querido. 
Vale observar que, em outras casas visitadas, o clima era festivo, as pessoas conversavam sobre diversos assuntos, relembravam o falecido e também faziam menção ao Brasil, quando nos percebiam como estrangeiros, demonstrando curiosidade sobre nossa estada e cultura, apontando os diferentes modos de lidar com a morte, processos de luto que dizem respeito a aspectos individuais e sociais.

Entendemos, por luto, um processo de construção de significado a partir do rompimento de um vínculo, no qual está presente a necessidade de significar a experiência da perda, em direção de se buscar a restituição do sentimento de segurança e de controle do mundo (Franco, 2010; Neimeyer, 2001/ 2013), que ficam abalados frente à morte de alguém significativo. Essa é uma experiência coletiva e individual, com a presença dos rituais cumprindo sua função social, ao mesmo tempo em que possibilitam, aos enlutados, atribuir um significado simbólico à sua perda, transcendendo o próprio sofrimento (Saporetti \& Silva, 2012).

O luto, na contemporaneidade, precisa ser visto a partir do paradigma da complexidade, pois é sabido que ele envolve distintas dimensões: individuais, familiares, sociais, culturais e espirituais. Esse tema demanda do psicólogo clínico, em especial daqueles que se dedicam ao trabalho com pessoas enlutadas, uma abertura para dialogar com outras áreas de conhecimento, em busca de ampliação da compreensão da experiência daquele que sofre a iminência ou a perda de alguém significativo. Não só as capacitações teórica, emocional e espiritual mostram-se fundamentais nesse percurso profissional, mas também o contato com culturas diversas, na maneira de significar a morte, o que é um importante diferencial no refinamento desse olhar clínico.

Com relação ao enfrentamento do luto, Stroebe \& Schut (1999) descreveram o modelo do processo dual como o de estratégias cognitivas a fim de lidar com a morte de alguém significativo. Nele, ocorre uma dinâmica de oscilação entre estressores relacionados à perda e estressores voltados para a restauração (momento relacionado à distração sobre o pesar), ou seja, acontece um movimento pendular que auxilia o enlutado a não ficar o tempo todo tomado pelo sofrimento que a perda do ente querido traz, tampouco absorvido pelas tarefas diárias que impeçam a vivência da dor (Guedes, 2018). Como apontou Guedes (2018), essa dinâmica dual representa a própria elaboração da perda, em que as memórias são revisitadas, as histórias recontadas e ressignificadas, quer dizer, um desenvolvimento processual que promove a construção gradativa de novos significados para o mundo, na ausência da pessoa amada, ao invés de um momento em que, simplesmente, o luto acabe.

A data que finda as festividades é o 2 de novembro, dia em que as famílias vão ao cemitério se despedir dos seus entes queridos, ornamentando as tumbas com os altares das casas, que são desmontados e levados para o rito final. A partir das oito da manhã, as famílias começam a chegar ao cemitério e, ao longo de todo o 
dia, compartilham a vivência com música - levada pela família ou através dos mariachis que circulam pelo cemitério e param quando são chamados pelas famílias para se apresentar-, com o compartilhamento de comida, bebida, conversa e orações. Há tumbas somente com flores; mesmo que sem a presença de altares, poucas se encontram abandonadas e sem qualquer adorno. Dentre as tumbas sem altar, há familiares presentes para garantir a salvaguarda da memória, mesmo sem a suntuosidade das homenagens, como é o costume no primeiro ano de morte. Às 12 horas é celebrada uma missa por um padre, em que cadeiras são arrumadas no boulevard principal da necrópole, de forma que as pessoas possam se acomodar mais confortavelmente. Ao final, há uma queima de fogos e, em seguida, as famílias se confraternizam, compartilhando os alimentos, ou retornam para suas casas, realizando o congraçamento entre si.

Dessa forma, a execução dos rituais é importante fator de proteção para o luto, devendo acontecer de acordo com as regras culturais e sociais de um determinado grupo/sociedade, pois dão contorno à vivência do processo de luto tanto individual quanto coletivamente.

\section{CONSIDERAÇÕES FINAIS}

A partir do que pôde ser conhecido com relação à maneira com que a comunidade compartilha a festa, foi possível perceber o sincretismo e a transmissão espontânea dos rituais, independentemente da religião à qual estejam ligados. Isso foi percebido na forma como o povoado se prepara e em como vivenciam os ritos, por exemplo: na porta da principal igreja católica do local, havia um cartaz diferenciando esta festividade do halloween. "A construção dos relatos orais, mesclando o passado e o presente, cristaliza e torna emblemática essa festividade, pois narram e interpretam o passado em um momento particular que é o presente" (Lemos, 2009b, p. 7)

A maneira como é recebido o espírito da pessoa falecida, assim como o fato de existirem dias distintos para se lembrar a morte de crianças e adultos, fomentaram as reflexões a respeito da diferença entre as culturas do México e do Brasil, com relação ao morrer. Neste país, a morte é um grande tabu e o Dia de Finados, data equivalente ao Dia dos Mortos, é comemorado com significados e sentimentos bastante diferentes dos que foram vistos naquele. Em Ocotepec, a morte é reverenciada, vista para além do mito da vida e juventude da modernidade; "da sentido à vida" (Villasenor \& Concone, 2012, p. 45) e as crianças aprendem sobre ela desde sempre, sendo incluídas na realização dos rituais.

Para profissionais que estudam sobre luto e que trabalham com pessoas enlutadas, a imersão numa rica experiência etnográfica possibilita uma revisita do mundo presumido, das perdas vividas e dos costumes/rituais familiares. Observar e vivenciar o Dia dos Mortos acentuou os questionamentos acerca da cultura da morte, do processo de morrer, da relevância dos rituais e do sentimento de pertencimento a um grupo durante um processo de luto, assim como 
incrementou a discussão a respeito do modelo dos vínculos contínuos, ao invés da manutenção de uma data final para a vivência do luto. Aliás, este ponto é muito importante quando olhado para a forma de o povoado lidar com seus entes queridos que morreram, em que há uma continuidade na relação e um cuidado em manter o vínculo para que os entes lembrem o caminho e os visitem ao voltar "à festa da vida" (Rodriguez, 2011).

Foi possível observar a vivência coletiva como forma de pertencimento, ratificando que as regras orientam e dão contorno em um momento em que as experiências individuais precisam encontrar um novo significado. Nesse aspecto também chamou atenção o caso de um grupo de jovens não pertencentes à cidade que morreram e não foram identificados, mas que o povoado considerou importante lembrar, dedicando-Ihes um altar em uma rua em que é identificada como local da morte.

No aspecto individual, nos chamou atenção a fala natural sobre a forma com que ocorreu a morte, por exemplo, no caso dos familiares que relataram suas perdas por suicídio, o que, vale ressaltar, na cultura brasileira, é considerado um interdito (dentro de um outro tema interdito, que é a morte). Isso trouxe questionamentos a respeito de como essa vivência acontece naquele contexto social, apontando para caminhos onde essa investigação possa ser aprofundada. O sincretismo religioso permeia as experiências de perda vividas pela comunidade, de forma que a vivência se torne algo natural e possível de conversa sem grandes tabus relacionados à maneira da morte. As religiões interferem sobremaneira em como as pessoas vivenciam seus lutos; no Brasil, por exemplo, em casos de morte por suicídio, ainda existe recriminação por diversos sistemas religiosos.

Portanto, os impactos dessas diferenças para a vivência dos lutos são um campo fértil para pesquisas, podendo auxiliar na compreensão do fenômeno e na implementação de ações na área da saúde que auxiliem na promoção do bemestar físico, emocional e espiritual. Dessa forma, é necessário identificar os aspectos envolvidos, de forma que os fatores de proteção para enfrentamento sejam valorizados e possamos falar, discutir e olhar mais para esse tema-tabu. Considerações que demonstram as contribuições dessa vivência para o crescimento profissional e pessoal das autoras.

Mostrou-se primordial a compreensão da morte e do luto pela psicologia e, ao mesmo tempo, o diálogo com demais áreas de conhecimento. Assim, consideramos salutar atuar na diminuição do tabu para que mais pessoas possam compreender e vivenciar seu processo de luto e os ritos de acordo com seu sistema de crenças. Com isso, atuamos na contramão do não reconhecimento do luto e validamos sua importância pessoal e coletiva.

Dada a relevância do assunto e o impacto que ele tem para a vida das pessoas, ressaltamos que a discussão é inesgotável e que novos estudos, com diferentes métodos, se fazem mais do que necessários, sempre respeitando as normas 
éticas, trazendo a possibilidade de amplitude na discussão, com um olhar interdisciplinar.

\section{REFERÊNCIAS}

Botelho, D. M., Darcie, M. \& Gobbi, M. C. (2019) Día de los Muertos no México: Uma análise folkcomunicacional. RIF, 17(38), 200-2016. doi:10.5212/RIF.v.17.i38.0012

Bowlby, J. (2002). Apego e perda: apego ( $3^{\mathrm{a}}$ ed.) (A. Cabral, Trad.). São Paulo: Martins Fontes.

Conaculta (2006). Patrimonio de la humanidad: la festividad indígena dedicada a los muertos en México. In Rojas, O. R. (Org.). Cuadernos 16. La festividad indígena dedicada a los muertos en México (pp. 14-22). Patrimônio Cultural y Turismo. México. Recuperado de https://www.cultura.gob.mx/turismocultural/publi/Cuadernos_19_num/cuaderno16.pdf.

Creswell, J. W. (2014). Investigação qualitativa e projeto de pesquisa ( $3^{\mathrm{a}}$ ed.) (S. Mallmann, Trad.). Porto Alegre: Penso.

Franco, M. H. P. (2010). Por que estudar luto na atualidade? In Franco, M. H. P. (Org.). Formaação e rompimento de vínculos: o dilema das perdas na atualidade (pp. 17-42). São Paulo: Summus.

Guedes, I. A. A. (2018). A espiritualidade frente ao processo de final de vida de um ente querido: reflexões sobre os significados atribuídos pelo familiar. (Dissertação de Mestrado). Pontifícia Universidade Católica de São Paulo, São Paulo.

Konno, S. (2018). A gramática da vida: reabitar o mundo no Día de Muertos em Oaxaca, 2917. Ponto Urbe [Online], (23). doi: 10.4000/pontourbe.4682.

Lemos, M. T. T. B (2009a). Marcas identitárias e resistência cultural: festas e rituais no México (pp. 111-124). Dossiê Identidade e Diferença na América Latina. Maracanan, n. 5. doi: 10.12957/revmar.2009.13640.

Lemos, M. T. T. B. (2009b). Práticas religiosas e representações simbólicas - Festas e ritualidades: o Dia dos Mortos no México. ANPUH - XXV SIMPÓSIO NACIONAL DE HISTÓRIA (pp. 1-7) Fortaleza.

Luján, J. E. M. (2006). Que viva en Día de Muertos: rituales que hay que vivir en torno a la muerte. In Rojas, O. R. (Org.). Cuadernos 16. La festividad indígena dedicada a los muertos en México (pp. 23-40). Patrimônio Cultural y Turismo. México. Recuperado de https://www.cultura.gob.mx/turismocultural/publi/Cuadernos_19_num/cuaderno16.pdf.

Minayo, M. C. S. O desafio do conhecimento: pesquisa qualitativa em saúde $\left(8^{\mathrm{a}}\right.$ ed.). São Paulo: Hucitec, 2004.

Neimeyer, R. A. (Ed.) (2013). Meaning Reconstruction \& the Experience of Loss. Washington: American Psychological Association, Kindle Edition.

Parkes, C. M. (1998). Luto: estudo sobre a perda na vida adulta (M. H. F. Bromberg, Trad.). São Paulo: Summus.

Parkes, C. M. (2009). Amor e perda: as raízes do luto e suas complicaç̃̃es (M. H. P. Franco, Trad.), São Paulo: Summus.

Rodríguez, J. L. (2011). Visión de la muerte em la cultura mexicana. Recuperado em 02 de setembro, 2020, de: http://www.contactomagazine.com/mexmuerte.htm.

Rodríguez, P. B. D., Moreno, A. H. \& Méndez, J. H. (2012). El altar de muertos: origen y significado en México. Revista de Divulgación Científica y Tecnológica de La Universidad Veracruzana, $X X V(1)$.

Recuperado

de: https://www.uv.mx/cienciahombre/revistae/vol25num1/articulos/altar/.

Rosenblatt, P. C. (1996). Grief does not end. In Klass, D., Silverman, P. R. \& Nickman, S. L. (Orgs.) Continuing bonds: new understandings of grief (pp. 3-27). Routledge.

Saporetti, L. A. \& Silva, A. M. O. P. (2012). Aspectos particulares e ritos de passagem nas diferentes religiões. In Carvalho, R. T. \& Parsons, H. A. (Orgs.). Manual de Cuidados Paliativos ( $2^{\mathrm{a}} \mathrm{ed}$.) (pp. 556-568). Academia Nacional de Cuidados Paliativos.

Silverman, P. R. \& Klass, D (1996). Introduction: what's the problem? In Klass, D., Silverman, P. R. \& Nickman, S. L. (Orgs.). Continuing bonds: new understandings of grief (pp. 3-27). Routledge.

Silverman, P. R. \& Nickman, S. L. (1996). Concluding thoughts. In Klass, D., Silverman, P. R. \& Nickman, S. L. (Orgs.). Continuing bonds: new understandings of grief (pp. 349-355). Routledge. 
Stroebe, M. \& Schut, H. (1999). The dual process model of coping with bereavement: rationale and description (pp. 197-224). Death Studies, vol. 23, n. 3. doi: 10.1080/074811899201046.

Villasenor, R. L. \& Concone, M. H. V. B. (2012). A celebração da Morte no imaginário popular mexicano. Revista Temática Kairós Gerontologia, 15(4), "Finitude/Morte \& Velhice" (pp. 3747), agosto.

\section{SOBRE AS AUTORAS}

Izabela Aparecida de Almeida Guedes é Mestre em Psicologia Clínica pela Pontifícia Universidade Católica de São Paulo - Laboratório de Estudos e Intervenção sobre o Luto - LELu. Psicóloga Clínica. e-mail: izabela-guedes@uol.com.br

(1) https://orcid.org/0000-0002-9644-636X

Maria Carolina Rissoni Andery é doutoranda em Psicologia Clínica pela Pontifícia Universidade Católica de São Paulo - Laboratório de Estudos e Intervenção sobre o Luto - LELu, Mestre em Psicologia Social pela Pontifícia Universidade Católica de São Paulo. Assistente Social e Psicóloga Clínica.

e-mail: carolandery@gmail.com

https://orcid.org/0000-0002-1669-2035

Claudia Marques Comaru é doutoranda em Psicologia Clínica pela Pontifícia Universidade Católica de São Paulo - Laboratório de Estudos e Intervenção sobre o Luto - LELu, Mestre em Saúde Pública pela Escola Nacional de Saúde Pública Sérgio Arouca/Fiocruz. Psicóloga Clínica.

e-mail: claudiacomaru@gmail.com

(1) https://orcid.org/0000-0002-3689-9674

\footnotetext{
${ }^{1}$ No original, Día de los Muertos. Neste artigo será usado o termo em português para referência a esse e outros termos referentes à festividade.

${ }^{2}$ In: https://masdemx.com/2016/10/simbolos-significados-dia-muertos-rituales-altar-mexico/

${ }^{3}$ Conceito concebido por Parkes (1971; 1996/ 1998; 2006/2009), que diz respeito ao modelo de mundo interno, construído a partir do nascimento, e que serve como referência para pensamentos e comportamento, ao longo da vida.
} 